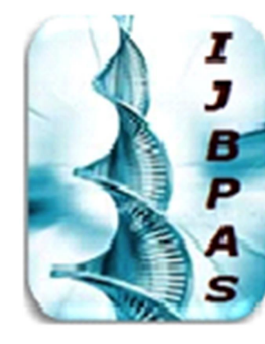

\author{
International Journal of Biology, Pharmacy \\ and Allied Sciences (IJBPAS) \\ 'A Bridge Betusen caboratorymd QRendor'
}

WwW.ijbas.com

\title{
COMPARATIVE REGULATORY FRAME WORK FOR CLINICAL DEVELOPMENT OF COVID 19 VACCINES AND THEIR FILING PROCEDURES IN INDIA, USA AND EUROPE
}

\author{
SHAILAJA P* AND KRISHNA SV \\ Assistant Professor, Department of Pharmaceutical Management and Regulatory Affairs Andhra \\ University of Pharmaceutical Sciences, Visakhapatnam \\ *Corresponding Author: E Mail: Dr. Pashikanti Shailaja: dr.pshailaja@andhrauniversity.edu.in \\ Received 19 ${ }^{\text {th }}$ Aug. 2021; Revised 20 ${ }^{\text {th }}$ Sept. 2021; Accepted $29^{\text {th }}$ Oct. 2021; Available online $1^{\text {st }}$ Dec. 2021 \\ https://doi.org/10.31032/IJBPAS/2021/10.12.2004
}

\begin{abstract}
The complexity of the COVID 19 pandemic has created a chaos in human life. Although various anti-viral drugs available to treat the COVID 19 but during this emergency situation the only solution to save humans is development of new vaccines to stop the spread of this pandemic. This has changed the way regulators look at the approval of new drugs/vaccines. The vaccines are not yet fully developed, and these new vaccines require a lot of work and patience to get approved. The major concerns about the vaccines are safety efficacy studies which are not completely established. Regulators have been trying very hard to bring flexibility in regulations so as to accelerate the approval process by considering the current pandemic situation. Many regulatory authorities providing approvals through the clause of Emergency Use Authorization (EUA). In this scenario, this paper will cover about various regulatory authorities of India (CDSCO Central Drugs Standard Control Organization), USA (Unites States Food Drug Administration) and Europe (European Medical Agency) and their legal regulations for development, manufacturing, licensing, import/export of the products to various countries etc. Technical regulations such as clinical data assessment such as safety and efficacy evaluation by using toxicity studies, trail population, study design. Complete information about the Phase I, Phase II, Phase III and Phase IV. Administrative regulations of the three countries such as filing procedures, licensing procedure and approval timelines by the regulatory authorities. Many of the vaccines are under Phase II \&Phase III trials. Since the Clinical data are not completely established the manufacturing organizations it becomes a huge challenge for the regulatory authorities to provide approval to the vaccine. Hence, they will only approve the vaccines only when the benefit to risk ratios exceed. All the manufacturing
\end{abstract}

\footnotetext{
IJBPAS, Decem6er, Special Issue, 2021, 10(12)
} 
organizations shall submit complete data after even attaining Emergency Use Authorization this include complete Phase III data and Phase IV data such as adverse reactions and post market surveillance. There are about 150 vaccine candidates are under study as per the World Health Organization. The ultimate goal of the regulators is to protect the human subject from disease and provide them with effective medication.

\section{Key words: Covid-19, FDA, Clinical Trials, Regulations, CDSCO}

\section{INTRODUCTION [1]}

Coronavirus disease (COVID-19) is an infectious disease caused by the SARS-CoV-2 (severe acute respiratory syndrome coronavirus 2) is a global pandemic that has severely affected lives and economies around the globe. The spread of the virus will be very difficult to contain if no vaccine is ready for implementation. Coronavirus is enveloped single-stranded positive-sense RNA viruses that belong to the family Coronaviridae. SARS Cov2 has recently emerged and has been declared a pandemic by World Health Organization. SARS-CoV-2 is a singlestranded RNA-enveloped virus. corona Virus are basically classified based upon genomic organization into the subfamily Coronavirinae that consist of four genera Alphacoronavirus $(\alpha \mathrm{CoV})$, Beta coronavirus $(\beta \mathrm{CoV})$, Gamma coronavirus $(\gamma \mathrm{CoV})$. Many countries are trying very hard to find the solution to these pandemics the only way to control this pandemic is complete vaccination. There has been a lot of research about the vaccines are under study. Usually, the development of the vaccines takes a lot of time, capital and extensive research; therefore, there is a lot of needed flexible regulations to get approval for the vaccines during these emergency situations. The regulatory authority mainly concerned about the safety of the vaccines on humans. As of date as per the WHO tracker dashboard. A number of vaccines in clinical development are 114 and Number of vaccines in preclinical development are 185 as on 2021/09/11 around the world. In this scenario, health authorities or regulatory authorities are strictly authored for approval only when their benefit ratio exceeds risk ratio. This paper will cover the legal, technical and administrative aspects of various vaccines that got approval and how the vaccines data gave the evidence of the safety for regulatory authorities and various regulations for vaccine development and approval pathway for three different countries India, USA and Europe.

\section{LEGAL REGULATIONS OF INDIA [2]}

The Government of India under ministry of health and family welfare (Department of health) the drug and cosmetics act and rules are framed-The Drugs and cosmetics Act 1940 under which the following are specified -All vaccines and Recombinant DNA (r-DNA) derived drugs shall be new drugs unless certified otherwise by the Licensing Authority under Rule 21

-FORM 26H Certificate of renewal of license to manufacture for sale of 2 [Large Volume Parenteral/Sera and Vaccines/recombinant 
DNA (r-DNA) derived drugs] specified in Schedules $\mathrm{C}$ and $\mathrm{C}(\mathrm{I})$ excluding those specified in Schedule X

SCHEDULE C: - Biological and Special Products. All vaccines shall be new drugs unless certified otherwise by the licensing authority approved under rule 21 of the Drugs and Cosmetic Rules, 1945. A copy of approval of the vaccine issued by the said licensing authority is to be enclosed, prior to issue of Registration Certificate of the said vaccines.

All vaccines shall be new drugs unless certified otherwise by the licensing authority approved under rule 21 of the Drugs and Cosmetic Rules, 1945. A copy of approval of the vaccine issued by the said licensing authority is to be enclosed, prior to issue of Registration Certificate of the said vaccines. Combined Vaccines. -Vaccines may be issued either singly or combined in any proportion in the same container. In the case of a combination of vaccines, a name for the combined vaccine may be submitted by the licensee to the regulatory Authority, and if approved, may be used as the proper name of the vaccine.

\section{LEGAL REGULATIONS OF UNITED STATES OF AMERICA [3]}

The office of the law revision counsel United States code describes the laws for food and drugs. The Federal Congress in 1938 has passed an act -The United States Federal Food, Drug and Cosmetic Act (FFDCA, FDCA OR FD\&C) under which The U.S. Food and Drug
Administration (FDA) can regulate the safety of food, drugs, medical devices and cosmetics. The Code of Federal Regulations describes under title 21 under chapter 1 Food and Drug Administration, Department of Health and Human Services subpart F describes about biologics. In 1820 a new age of United State of America drug regulation was established with the emergence of U.S. Pharmacopoeia. In 1906, Congress revised the previous act into Food and Drugs Act, which strictly suggest that drugs or Food must meet the pharmacopeia standards with respect to strength and purity. With the sulphanilamide tragedy the regulatory agency has further enacted the Federal Food, Drug and Cosmetics Act (1938) and added new provisions that new drugs should submit the complete information about the safety before getting marketing authorization

In 1962 The Kefauver-Harris Amendment Act was passed, which has set the rules that manufacturers must prove that the new drug must be safe and effective. The Food and Drug Administration (FDA) is responsible for protecting and promoting public health like general drug approval process, FDA's new drug approval process is also accomplished in two phases: Clinical Trials (CT) and New Drug Application (NDA) approval. The new drug product is controlled through a new drug application (NDA). Currently such applications are accepted for review in eCTD format. The major concern about NDA is that the product shall be safety and effective. FDA approval 
process begins only after submission of investigational new drug (IND) application. The US Drug Law and Regulations United States Pharmacopoeia (USP) were implemented in 1820 to set standards for strength and purity of drugs.

Major benchmarks in the emergence of US drug law are:

Food and Drugs Act (1906): It requires that drug must compile with the official standards of strength and purity.

- The Federal Food, Drug and Cosmetic Act (1938): amended after sulphanilamide tragedy, to prove the safety of a drug before being marketed.

- Kefauver- Harris Amendment (1962): It was passed after the thalidomide disaster. It requires the manufacturers to prove that the drug is safe and effective. Every firm should send an adverse effect report to FDA.

- $\quad$ Orphan Drug Act (1973): Under this act it specifies that there will be a tax exemption for the manufacturers who produce orphan drugs.

- FDA Modernization Act (1997): It contains minor changes in FD\&C Act which include the description about the fees and approval process

- Licensed biological products regulated by the Centre for Biologics Evaluation and Research (CBER): -Expediting clinical trials for preventive vaccines and other therapeutic biological products that hold promise to prevent or treat COVID-19 by providing timely advice and interactions

Biological Product Deviation Reporting (CDER). All biological products deviation report will be received by the Centre for Drug Evaluation and Research, Food and Drug Administration (FDA) assisted by the office of compliance and risk assessment.

Under this section, an applicant must inform the FDA about any minor changes, including the changes in equipment, quality controls, facilities, change in manufacturing site, labelling, and change in the personnel should be informed to the regulatory authority.

Before a product can be sold, an applicant must assess the effect of a change on the product's safety and effectiveness. This assessment must be done through a clinical study or other laboratory studies that demonstrate the lack of adverse effects from the change.

The applicant must promptly revise all promotional labelling and advertising to make it consistent with any labelling change implemented in accordance with the specification or guidelines.

\section{LEGAL REGULATIONS OF EUROPE [4]}

In the year 1995 European Medicines Evaluation Agency (EMEA) was established in London, which coordinate the European Union state members for evaluating and supervising the medicinal products for both human and veterinary use. The approval of drugs for European Union member states is carried out in two phases. The first is the clinical trial, while 
the second is the marketing authorization. A clinical trial application will be filed to a regulatory authority within European Union. The clinical trials are conducted only after the approval. Marketing authorization application is filed only after all the three phases of clinical trials are completed.

The European Medicines Regulatory System is based on a unique network of around 50 regulators from the 28 European Union Member States. This system makes the system unique

TECHNICAL REGULATIONS OF VACCINES IN USA, INDIA AND EUROPE [5]

- For biological products, the approval comes from FDA authority through the Federal Food Drugs and Cosmetics act. The procedure for vaccine approval and regulation including preclinical testing, human testing and post-approval safety monitoring. The FDA centre for biologics is evaluated and research is responsible for vaccine approval and regulations.

- Vaccine approval comes under FDA authority through the federal food drugs and cosmetics act and is also governed by the public service act, which regulates biological products. The process and requirements for vaccine approval and regulation therefore follow a pattern similar to those for other medical products, including preclinical testing, human testing and post-approval safety monitoring. The FDA centre for biologics is evaluated and research is responsible for vaccine approval and regulations.

- Once in-vitro testing and animal studies help identify the appropriate dosage and provide pharmacokinetics and toxicology data, manufacturers submit an IND application to the FDA. IND (Investigational New Drug) must contain preclinical data, a description of planned human trail. After this only a trail can be procced. If FDA raises any concerns regarding safety efficacy FDA may request to pause the clinical trial.

- Phase I: - Clinical studies assess vaccine safety, dosage and capacity to induce an immune response in small Number of health subjects

- Phase II: -Trial Evaluates initial safety and efficacy in large population perhaps few hundreds of participants' goal of phase II testing are to study the vaccine safety, immunogenicity, dose-ranging.

- Phase III: - Phase III studies depicts whether the product offers a treatment benefit to a target population. Sometimes known as pivotal studies, these studies involve 300 to 3,000 participants. Phase studies provide most of the safety data. In previous studies, it is possible that less common side effects might have gone undetected. Because these studies are larger and longer in duration, the results are more likely to show long-term or rare 
side effects. Many regulatory authorities insist on this phase as this phase generate pivotal data supporting FDA approval. The main concerns about this trail are Efficacy and monitoring of adverse reactions

- Phase IV: - Phase 4 trials are carried out once the drug or device has been approved by FDA during the Post-Market Safety Monitoring. Any adverse drug reactions are reported in a near long-term

\section{TOXICITY STUDIES [6]}

- For a COVID-19 vaccine candidate consisting of a novel product type and for which no prior nonclinical and clinical data are available, nonclinical safety studies will be required prior to proceeding to clinical trials as per $21 \mathrm{CFR}$ 312.23

- Data from toxicity studies may be submitted as unaudited final draft toxicrologic reports to accelerate proceeding to FIH clinical trials with COVID-19 vaccine candidates. The final, fully quality-assured reports should be available to FDA within 120 days of the start of the FIH clinical trial

Efficacy Considerations: - Standardization of efficacy endpoints across clinical trials may facilitate comparative evaluation of vaccines for deployment programs, provided that such comparisons are not confounded by differences in trial design or study populations. To this end, FDA recommends that either the primary endpoint or a secondary endpoint (with or without formal hypothesis testing) be defined as virologically confirmed SARSCoV-2 infection with one or more of the following symptoms: o Fever or chills o Cough o Shortness of breath or difficulty breathing or Fatigue or Muscle or body aches o Headache or new loss of taste or smell of Sore throat o Congestion or runny nose, Nausea or vomiting or Diarrhoea.

Safety Considerations: - The pre-licensure safety database for preventive vaccines for infectious diseases typically consists of at least 3,000 study participants vaccinated with the dosing regimen intended for licensure. FDA anticipates that adequately powered efficacy trials for COVID-19 vaccines will be of sufficient size to provide an acceptable safety database for each of younger adult and elderly populations, provided that no significant safety concerns arise during clinical development that would warrant further pre-licensure evaluation.

Table 1: Various types of vaccines under clinical development or approved vaccines in the USA

\begin{tabular}{|c|c|c|c|c|c|}
\hline Vaccine & Type of Vaccine & Vaccine Regime & Efficacy details & Status & Storage \\
\hline $\begin{array}{c}\text { Moderna } \\
\text { Vaccine m-RNA } \\
1273\end{array}$ & RNA vaccine & $\begin{array}{c}2 \text { doses 100 } \\
\text { micrograms,28 } \\
\text { days apart }\end{array}$ & $\mathbf{9 4 \%}$ & Phase III & +2 to $+\mathbf{8}^{0} \mathrm{C}$ \\
\hline $\begin{array}{c}\text { Janssesn } \\
\text { COVID 19 } \\
\text { Vaccine }\end{array}$ & VVNR & $\begin{array}{c}2 \text { doses 60 } \\
\text { micrograms, 28 } \\
\text { days apart }\end{array}$ & $\mathbf{8 1 \%}$ & Phase III & +2 to $+8^{0} \mathrm{C}$ \\
\hline Pfizer Vaccine & m-RNA & 2 Doses & $\mathbf{9 5 \%}$ & Phase III & $\mathbf{- 7 0}^{0} \mathrm{C}$ \\
\hline
\end{tabular}


Table 2: Various types of vaccines under clinical development or approved vaccines in INDIA

\begin{tabular}{|c|c|c|c|c|c|}
\hline Vaccine & Type of Vaccine & Vaccine Regime & Efficacy details & Status & Storage \\
\hline Covaxin & $\begin{array}{c}\text { Inactivated } \\
\text { Vaccine }\end{array}$ & $\begin{array}{c}\mathbf{2} \text { doses } 28 \text { days } \\
\text { apart }\end{array}$ & $\mathbf{8 1 \%}$ & Phase III & $+\mathbf{2}$ to $+\mathbf{8}^{0} \mathbf{C}$ \\
\hline Covisheild & $\begin{array}{c}\text { Viral Vector } \\
\text { Vaccine }\end{array}$ & $\begin{array}{c}\mathbf{2} \text { doses 12 weeks } \\
\text { apart }\end{array}$ & $\mathbf{8 2 \%}$ & Phase III & $+\mathbf{2}$ to $+\mathbf{8}^{0} \mathrm{C}$ \\
\hline
\end{tabular}

Table 3: Various types of vaccines under clinical development or approved vaccines in

\begin{tabular}{|c|c|c|c|c|}
\hline Vaccine & Vaccine type & Vaccine regime & Status & Storage \\
\hline Comirnaty & mRNA & 2 doses & Phase III & $\mathbf{2}^{\mathbf{0}}$ to $10^{\circ} \mathbf{C}$ \\
\hline Vaxzervria & Protein subunit & 2 doses & Phase III & $\mathbf{- 8}^{\mathbf{0}} \mathbf{T O - 2 ^ { \circ }} \mathbf{C}$ \\
\hline
\end{tabular}

ADMINISTRATIVE REGULATIONS OF VACCINES

\section{VACCINE FILING PROCEDURE IN USA}

[7]

\section{Investigational New Drug Application (INDA) [7]}

It is an application filed to FDA prior to human testing. It gives a full description of chemistry, manufacturing and controls, pharmacology and toxicology information, any previous human experience.

Types of IND: An Investigator IND: An IND shall be submitted by a sponsor who will take an initiative and conducts an investigation. A sponsor shall submit a research IND to depict the research of an unapproved drug, or an approved product.

Emergency Use IND: This allows the FDA to authorize use of an experimental drug in an emergency situation that does not allow time for submission of an IND.

Treatment IND: This IND is filed when an experimental drug which is showing promising results in clinical testing in case of a serious or immediate life-threatening conditions. All the clinical work conducted shall be reviewed by FDA

\section{The two IND categories are commercial and} research (non-commercial) types.

The IND application must broadly include the following areas: (1) Animal Pharmacology and Toxicology Studies (2) Manufacturing Information and (3) Clinical Protocols and Investigator Information. Once an IND is filed FDA will take 30 calendar days to provide an update until then an applicant is not allowed to perform the clinical trial. During this period FDA will review the data submitted in gives an update considering the safety and efficacy details.

New Drug Application (NDA) [8]: A New Drug Application is filed to get approval for marketing a new drug in the USA. An NDA contains information included in the IND, as well as the results of clinical studies proving safety and efficacy. The FDA shall start the review process within 60 days from the submission of an NDA. Contents and Format of NDA Two copies of the application are: (a) Archival copy and (b) Review copy. 
A) Archival Copy: It serves as a reference source for FDA reviewers to locate information not contained in the review copy; and it contains copies of tabulations and clinical study case report forms. It contains the following elements:

Application form FDA 356, Index, Summary, Technical sections, Chemistry, manufacturing and controls section, Non-clinical pharmacology and toxicology section, Human pharmacokinetics and bioavailability section, Microbiology section, Clinical data section, Statistical section, Paediatric use section, Samples and Labelling.

B) Review Copy: Each technical section is separately bound in each folder. Each technical section should contain:

1. Index, Copy of FDA Form 356, Copy of cover letter, Letters of authorization, Copy of application summary.

Licensure of vaccines will be done by three procedures which include obtaining approval from Food and Drug Administration (FDA), and this process will take certain years or even some decades for the manufacturers to start providing vaccines. For example, it took almost eleven years to get approval for varicella vaccine.

To attain license for manufacturing and distribution of a vaccine it becomes more complex and time consuming for the manufacturing firm and the regulatory authority (FDA). As a sponsor or manufacturing firm they should first pilot lots for research purpose which include preclinical testing in animals. Sponsor shall submit a notice of claimed investigational exemption after completing the clinical testing in humans. Hence the product is considered as Investigational new drug. An IND must include all the data of the product which include

1) A detailed explanation of Composition, source and manufacturing process of the product.

2) Various Quality Control test for proving the safety, purity and potency of the vaccine/product.

3) All the pre-clinical data and laboratory data.

4) Complete information about the performer/investigator during a 30-day waiting period, the IND application is reviewed by the FDA to determine whether human subjects will be exposed to unwarranted risks.

\section{Biological License Application (BLA)}

The Biologics License Application (BLA) is a request for permission to introduce, or deliver for introduction, a biologic product into interstate commerce (21 CFR 601.2). The BLA is regulated under 21 CFR $600-680$. A BLA is submitted by any legal person or entity who is engaged in manufacture or an applicant for a license who takes responsibility for compliance with product and establishment standards. Form 356h specifies the requirements for a BLA. This includes: Applicant information, Product/Manufacturing 
information, Pre-clinical studies, Clinical studies, and Labelling.

\section{ESTABLISHMENT}

LICENSE APPLICATION (ELA) [9]

The vaccine producing firm shall also submit Establishment License Application and the following data should be submitted.

1) Organizational and personnel details of the performer, Site area of manufacturing and work premises, Detailed note on Equipment and the systems used, Labelling templates and packaging including secondary packaging images. Reports and results of the data which shall be recorded and labelling guidelines

\section{Emergency Use Authorization EUA [9]}

Under section 564 of the Food Drugs and Cosmetics Act Emergency Use Authorization (EUA) is granted. This will be granted when the potential benefit of a product overrides the risk of the product in case of a severe lifethreatening diseases. In order to obtain Emergency Use Authorization, the manufacturer shall prove that the clinical trial phase I and Phase II data should be in such a way that there will not be any harm to the human subjects. The manufactures shall submit all the data after performing the phase III clinical study.

Administrative Regulations of India [10]: Vaccines in India are regulated by CDSCO (central drugs standard control organization). The general phase for vaccine filing procedures is represented below. For obtaining approval for a new vaccine a new Investigational New Drug application there is a need to be submit the chemistry, clinical and non-clinical data of the vaccines. There will be an assessment of the bioequivalent and bioavailability studies and safety studies will be done by the health authority.

\section{ADMINISTRATIVE REGULATIONS EUROPE [10]}

Centralized Procedure: -In this procedure, applications are accepted with regards to products of biotechnological sciences and New Chemical Entities (NCEs). The EMEA staff, on receiving the Marketing Authorization Approval (MAA), checks the completeness and compliance of the application with EU guidelines. This appraisal must be completed within ten days from the date of filing the application. The sponsor pays the appropriate fees. Then, EMEA has 210 days to consider the application. It can appoint rapporteurs, who assess the application and report Committee for Medicinal Products for Human Use (CHMP). CHMP gives an opinion on whether to accept or reject the application; it is forwarded to the European Commission, which can take 90 days to arrive at a decision. The total time for approval is around 300 days $(210+90)$ 


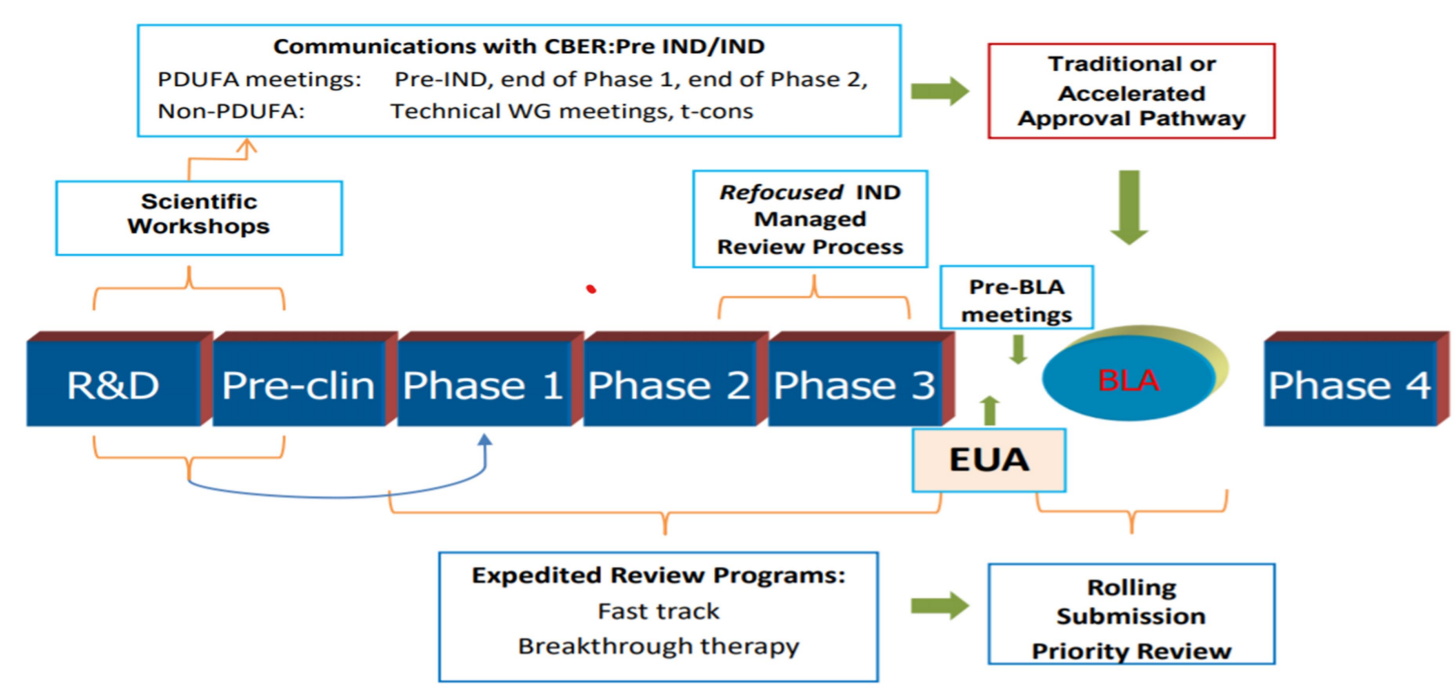

Figure 1: Approval Pathway in India

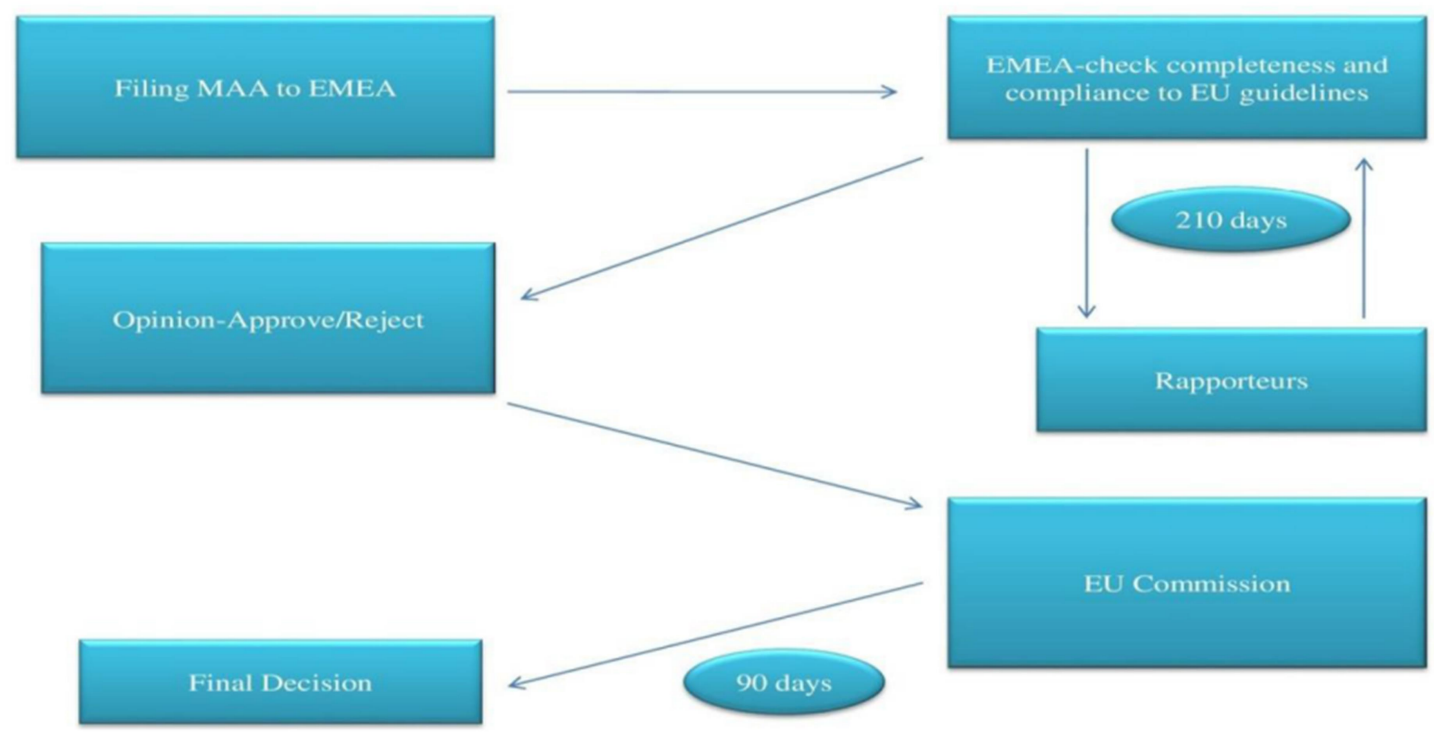

Figure 2: Centralized Procedure

\section{Decentralized Procedure [10]}

Under this, a product is recognized by a group of member's countries simultaneously. It is considered as very efficient procedure. Decentralized procedure is followed to obtain marketing authorizations in several member states. The sponsor submits to a national regulatory authority, the application and a list of all Concerned Member States (CMSs), specifying a Reference Member State (RMS).
The RMS must validate the application and Summary of Product Characteristics (SPCs); prepare a draft assessment report within 210 days and send a copy to the CMSs; this report can be approved within 90 days. If the product caused any adverse effect on human. CMSs can raise any objections and then the CHMP intervenes and takes a final decision within 30 days. However, a negative decision can affect the registration in many countries under this 
scheme also following products cannot be registered: Orphan drugs, all biological products, cancer-treating drugs, anti-viral drugs, and Auto-Immune Diseases. National Procedure in Europe, each nation has its own regulatory body. National procedure is the procedure adopted by each nation independently of other nations. The fees are affordable even for small firms. It saves on translation cost to English or regional languages. It creates a base for Mutual recognition Procedure Biotechnical procedures cannot be registered through national procedure. The Centralized filing through EMA is compulsory for the same. The application, submitted by the sponsor under the national rules to the national competent authority, is reviewed and a marketing authorization is granted. Under this scheme also following product cannot be registered: Orphans Medicinal Product, All Biotechnology Based Product, Specified Aids and Cancer Medicines, Specified Antiviral Medicines, Specified Medicines for Neurodegenerative Disorder including diabetes and Specified Medicines for Autoimmune Diseases/dysfunctions

\section{Mutual Recognition Procedure (MRP)}

Under this a product registered in one country is mutually recognized by the other country. The application is required to make application only once for initial registration. The same application with some regional changes is accepted by another member country. Assessment Report of medicinal Product by Member Countries in EU: During Mutual recognition process the assessment report of the Reference member state is reviewed before granting approval. The submission can be made to any number of the other member states and the RMS sends a copy of the assessment report to the Concerned Member States (CMSs), who can raise any objections within 90 days. Each CMS issues a national marketing authorization with an identical (Summary of Product Characteristics) SPC. Under this scheme following products cannot be registered: Orphans Medicinal Product, all biotechnology-based products, Specified Aids and cancer Medicines, Specified Antiviral Medicines, Specified Medicines for Neurodegenerative Disorder including diabetes and Specified Medicines for Autoimmune Diseases/ dysfunctions.

\begin{tabular}{|c|c|c|c|}
\hline \multicolumn{2}{|c|}{ Table 4: Manufacturing and control requirements } \\
\hline $\begin{array}{c}\text { Requirements } \\
\text { batches }\end{array}$ & India & EU & U3 \\
\hline Packaging & Not addressed & Not required & A minimum of 1,00,0000 \\
\hline $\begin{array}{c}\text { Process } \\
\text { validation }\end{array}$ & Required & Required & Not required at the time of submission \\
\hline Batch size & Pilot-scale batch & $\begin{array}{c}\text { 2 pilot-scale plus 1 lab batch or minimum of } \\
\text { one lakh units } \\
\text { whichever is higher }\end{array}$ & $\begin{array}{c}\text { 1 pilot-scale or minimum of one lakh } \\
\text { units } \\
\text { whichever is higher }\end{array}$ \\
\hline
\end{tabular}




\begin{tabular}{|c|c|c|c|}
\hline Requirements & India & $\mathbf{E U}$ & US \\
\hline Agency & $\begin{array}{l}\text { Single agency } \\
\text { DCGI (CDSCO) }\end{array}$ & $\begin{array}{c}\text { Multiple agencies } \\
\text { EMAIL } \\
\text { CHMP } \\
\text { National health agencies }\end{array}$ & Single agency USFDA \\
\hline Registration process & $\begin{array}{l}\text { Single registration } \\
\text { process }\end{array}$ & $\begin{array}{c}\text { Multiple registration process } \\
\text { Centralized (European community) } \\
\text { Decentralized (at least } 2 \text { member } \\
\text { states) } \\
\text { Mutual recognition (at least } 2 \\
\text { member states) National } \\
\text { member } r \text { state) }\end{array}$ & Single registration process \\
\hline TSE/BSE study data & Required & Required & Required \\
\hline Braille code & $\begin{array}{l}\text { Braille code is not } \\
\text { required on } \\
\text { labelling }\end{array}$ & Braille code is required on labelling & $\begin{array}{c}\text { Braille code is not required on } \\
\text { labelling }\end{array}$ \\
\hline Post-approval changes & Major-Moderate & \begin{tabular}{|c} 
Post Variation in approved drug Type \\
IA \\
Type IB \\
Type II
\end{tabular} & $\begin{array}{l}\text { Minor } \\
\text { Moderate } \\
\text { Major }\end{array}$ \\
\hline
\end{tabular}

\section{CONCLUSION}

This Pandemic Created a Chaos to the human life hence resulted development of various vaccines. Therefore, there is a need for flexibility of the regulations by balancing the safety parameters so that human subjects are saved. Emergency use authorization granted approval for various vaccines considering the current situation. Therefore, there must be a strict regulation to be followed and all the data about the vaccines should be submitted without any conspiracy.

Conflict of Interest Declaration: - No conflict of interest.

\section{REFERENCE:}

[1] https://www.ncbi.nlm.nih.gov/pmc/arti cles/PMC7286265/

[2] https://legislative.gov.in/sites/default/fi les/A1940-23.pdf
[3] https://www.cdc.gov/phlp/publications/ topic/vaccinationlaws.html,

[4] https:/www.euro.who.int/en/healthtopics/disease-prevention/vaccinesand-

immunization/publications/2021/operat ional-guidance-legal-and-regulatoryframework-facilitating-vaccinedeployment,-january-2021-producedby-whoeurope

[5] https://www.fda.gov/files/drugs/publis hed/Investigational-New-DrugApplications-Prepared-and-Submittedby-Sponsor-Investigators.pdf

[6] "Evaluation of the Safety and Immunogenicity of SII Vaccine Constructs Based on the SARS-CoV-2 (COVID-19) Variant in Adults". clinicaltrials.gov. 
September 2021. NCT05029856.

Retrieved 16 September 2021.

[7] https://www.fda.gov/drugs/investigatio

nal-new-drug-ind-application/ind-

application-procedures-overview

[8] https:/www.fda.gov/vaccines-blood-

biologics/development-approval-

process-cber/biologics-license-

applications-bla-process-cber.

[9] An article on Understanding FDA

Regulatory Requirements for Investigational New Drug Applications for Sponsor-Investigators doi: 10.231/JIM.0b013e3181afdb26.

[10] An review article on Regulatory Requirements and Drug Approval Process in India, Europe and US Sawant AM, Mali DP and Bhagwat DA DOI: $\quad 10.4172 / 2167-$ 7689.1000210 